\title{
ARTHUR DE GOBINEAU E GILBERTO FREYRE: UM ENCONTRO IMPROVÁVEL, UMA APROXIMACÃO POSSÍVEL
}

\author{
Helga Gahyva* \\ Universidade Federal do Rio de Janeiro - Brasil
}

Resumo: Gilberto Freyre já foi descrito com as mesmas palavras por meio das quais caracterizava o Brasil: um luxo de antagonismos em equilibrio. Contribuíram decisivamente para essa coincidência as múltiplas possibilidades de leitura ensejadas por sua obra. A se considerar, por exemplo, seu livro de estreia, Casa-grande \& senzala (1933), chama a atenção seu impacto inovador nas letras nacionais, tanto em função de sua perspectiva metodológica quanto de sua versão positiva para a então malsinada identidade brasileira. Mas há chave de leitura alternativa - e não excludente: a narrativa freyriana sobre a formação de nossa sociedade patriarcal, sobremaneira se aliada aos dois outros volumes da trilogia - Sobrados e mocambos (1936) e Ordem e progresso (1958) -, encerra elementos que lhe conferem afinidades com autor à primeira vista - ou a certa vista - antagônico: Arthur de Gobineau. Trata-se de deslocar para segundo plano o tema racial, conferindo protagonismo à narrativa comum revelada pelo elogio a instituições ligadas historicamente ao mundo feudal, especialmente a família.

Palavras-chave: Arthur de Gobineau, Gilberto Freyre, pensamento conservador, pensamento social brasileiro.

Abstract: Gilberto Freyre has already been portrayed by the same words he himself used to describe Brazil: a display of antagonisms in balance. The multiple ways of interpreting his work contribute to this coincidence. For instance, when considering his career's opening book, Masters and slaves (1933), what draws attention is its impact on the Brazilian literature for its methodological perspective as well as his positivistic interpretation of the, at the time considered unfortunate, Brazilian identity. Nevertheless, there is a key to an alternative - but not exclusive-understanding: the

* Contato: helga.gahyva@gmail.com.

Horizontes Antropológicos, Porto Alegre, ano 21, n. 44, p. 371-390, jul./dez. 2015 http://dx.doi.org/10.1590/S0104-71832015000200015 
freyrian narrative about the formation of the national patriarchal society. This narrative, greatly if combined with the other two volumes of his trilogy: Mansions and shanties (1936) and Order and progress (1958), contains elements which lend him affinity with Arthur de Gobineau, at first sight, or to a certain degree, an antagonist. This is done by shifting aside the racial question and putting up front their shared narrative, revealed by their common eulogy to institutions that can be traced historically to the feudal world, especially the family.

Keywords: Arthur de Gobineau, Brazilian social thought, conservative thought, Gilberto Freyre.

\section{Introduç̃o}

Pode ser profundo o abismo que separa Arthur de Gobineau de Gilberto Freyre. O primeiro, nascido em 1816, francês de Bordeaux, migrado a contragosto para Paris, viu-se frequentemente obrigado a adaptar suas ambições científicas e literárias à vida itinerante - e, sob seu ponto de vista, nem sempre agradável - de diplomata. A desejada independência financeira, que lhe possibilitaria sobreviver apenas de seus escritos, jamais fora alcançada: seus estudos históricos e suas obras de ficção tiveram pouco impacto à sua época e ele morreu, em 1882, sem suspeitar do sucesso que brevemente a posteridade conferiria ao seu Essai sur l'inégalités des races humaines (1853-1855), ${ }^{1}$ granjeando-lhe, doravante, o epíteto de pai do racismo moderno (Cassirer, 1997). ${ }^{2}$

O segundo, pernambucano nascido em 1900, ligado genealogicamente ao universo patriarcal da casa-grande colonial, era já um jovem conhecido nos meios políticos locais quando, em retorno dos Estados Unidos, publicou sua obra inaugural, Casa-grande \& senzala, em 1933 (Freyre, 2006). Apontei em outro artigo a fulgurosa repercussão atingida pelo livro (Gahyva, 2011a); entre críticas, elogios e dúvidas, uma quase unanimidade: munido de instrumental teórico e metodológico original, Freyre revolucionara as ciências sociais brasileiras. As consequências de sua narrativa heterodoxa extrapolara o âmbito acadêmico, pois, munido da sugestão boasiana quanto à separação

1 Doravante denominado apenas Essai (Gobineau, 1983a).

2 Para informações biográficas sobre Gobineau ver Boissel (1993) e Gahyva (2012a, p. 57-106).

Horizontes Antropológicos, Porto Alegre, ano 21, n. 44, p. 371-390, jul./dez. 2015 
entre os efeitos de raça e de cultura, ele positivava a miscigenação étnica que tanto atormentava nossa primeira geração republicana, alçando-a à condição de elemento-chave da identidade nacional brasileira. Casa-grande \& senzala, enfim, atropelou os postulados do determinismo racial tão caros à intelligentsia brasileira que, pelo menos desde o fim dos anos 1880, eventualmente recorria à obra de Gobineau para compreender as causas de nosso “atraso”.

Ao contrário do francês, Freyre conheceu cedo a notoriedade, tornando-se raríssimo caso de intelectual brasileiro capaz de viver apenas de suas obras - não à toa, ele preferia ser chamado de escritor (Freyre, 1950, p. 12; Kujawski, 1981, p. 15). Se Gobineau morreu amargando o fardo do fracasso, o pernambucano atravessou o século XX ostentando a qualificação de mais importante intelectual brasileiro - ainda que, por um lado, frequentemente manifestasse desagrado com o que considerava acolhida mais vigorosa fora do que dentro do país; e, por outro, tenha visto maré crescente de críticas às suas perspectivas, sobretudo políticas (Freyre, 1943, p. 33; Pesavento, 2006, p. 42).

A partir da segunda metade do século XX, os estudos de Freyre sobre a formação da sociedade patriarcal brasileira tornaram-se alvo de comentários desabonadores que lhes censuravam o "traço pouco acadêmico" (Mota, 1977, p. 56), derivado do "primado do subjetivismo" (Leite, 2002, p. 360). Mas se as novas gerações de pesquisadores, reunidas sobretudo em torno da Universidade de São Paulo, destacavam suas limitações, não faltaram aqueles que, dos anos 1930 às primeiras décadas do século XXI, insistiram no potencial inovador das suas contribuições metodológicas (Sevcenko, 2001).

Às críticas ao seu estilo ensaístico (Mota, 1977, p. 59), Freyre muitas vezes retrucava implicitamente por meio de seu combate à especialização excessiva. Não deixava, porém, de salientar os riscos do "generalismo perigosamente vizinho do saber dos diletantes” (Freyre, 1973, p. 78). Munido de credenciais científicas, ele desprezava os extremos, defendendo a "inter-relação de saberes” (Freyre, 1973).

Gobineau mantinha-se savant em um mundo cada vez mais colonizado por cientistas. À medida que o campo acadêmico se institucionalizava, ele também denunciava as amarras da especialização. À diferença de Freyre, contudo, suas críticas traduziam-se em recusa radical. Um exemplo bastante ilustrativo: em 1878, ele tenta, sem sucesso, publicar uma segunda edição de seu ensaio sobre as raças. Na dúvida quanto à atualização de sua narrativa à luz das intensas modificações pelas quais passa a biologia na segunda metade 
do Oitocentos, ele se dedica ao estudo do darwinismo, porém o rechaça, negando-se a incorporar quaisquer sugestões, mesmo críticas, à nova edição (Raeders, 1938, p. 368).

Mas o abismo entre eles pode ser ainda mais profundo: "É coisa que passou / Com o franciú Gobineau / Pois o mal do mestiço / Não está nisso", lembra Manuel Bandeira em poema intitulado Casa-grande \& senzala. Freyre seria, portanto, o anti-Gobineau, pois capaz de revelar a precariedade do argumento racialista em face da abordagem culturalista. Ou seja, no que diz respeito à central temática racial, o divórcio seria evidente e a tal "aproximação possível”, sugerida no subtítulo deste artigo, uma falácia.

Poder-se-ia, entretanto, investir na proximidade seguindo pistas sugeridas por Costa Lima. Segundo ele, Freyre teria procedido à recepção deveras limitada de Franz Boas: ainda que Casa-grande \& senzala tenha, de fato, "rompido com o esquema interpretativo que até então havia dominado entre nós [...] o fator étnico continua a ser fortemente destacado por Gilberto Freyre” (Lima, 1989, p. 198, 207). O papel conferido à raça na economia interna de seu argumento afastaria o autor de uma pura inscrição culturalista (Lima, 1989, p. 208).

Nessa chave, talvez fosse possível examinar em qual medida a narrativa freyriana, a despeito de suas intenções explícitas, manteria elementos passíveis de serem aproximados à concepção racial de Gobineau. Não é esse, todavia, o objetivo do presente artigo. Menos do que "racializar" a perspectiva do pernambucano, interessa-me "desracializar" o discurso do diplomata.

Já mostrei em outros trabalhos como, na obra do francês, o argumento racialista fornece vocabulário moderno à sugestão própria ao século XVIII: trata-se da tentativa de fundamentar ontologicamente o movimento por meio do qual as antigas sociedades de ordens cederam espaço à igualdade legal (Gahyva, 2011b, 2012a).

O determinismo racial simultaneamente explicaria a derrota da aristocracia e estabeleceria novo padrão hierárquico a sociedades composta por homens estatutariamente iguais. No primeiro caso, ele teria sido bem-sucedido no esforço de produzir uma narrativa que, sob o léxico racial, constituir-se-ia como a "epopeia da decadência” (Dreyfus, 1933, p. 595) de um grupo social, mas teria falhado no fundamento da hierarquia própria aos novos tempos, pois, no Essai, ele conclui pelo esgotamento do regenerador sangue ariano (Gobineau, 1983a, p. 1166). Como, então, estabelecer um princípio de 
distinção irrealizável no presente? Para driblar esse obstáculo, Gobineau substituiu sua concepção de nobreza de raça pela de nobreza espiritual (Gahyva, 2008, p. 284).

Mas a passagem da hierarquia racial à individual, manifesta no romance Les Pléiades, de 1874 (Gobineau, 1983b), tem vida curta. Em sua derradeira obra, Histoire d'Ottar Jarl: pirate norvégien, conquérant du pays de Bray en Normandie et de sa descendance (Gobineau, 1879), ${ }^{3}$ ele recorre às suas supostas origens genealógicas na tentativa de fundar um novo critério distintivo: a hierarquia familiar. Conforme sintetizei alhures,

[...] nem a generalidade de um fundamento racial que [...], além de hodiernamente inócuo, agrupava sob uma mesma coletividade elementos moralmente díspares; nem o individualismo atomista ao qual poderiam conduzir as reflexões esboçadas em Les Pléiades. Se o Essai dizia que o homem não existia senão como membro de sua raça e, naquele romance, ele só escapava à animalidade recolhido em seu pleno individualismo (Gobineau, 1983b, pp. 18-19), a síntese viria em Ottar Jarl: o homem só adquire sentido na qualidade de membro da família. (Gahyva, 2013, p. 250-251).

Ao deslocar o argumento racialista para segundo plano, torna-se possível encurtar o abismo entre Gobineau e Freyre e, mais ainda, explicitar o objetivo deste artigo: trata-se de proceder a um esforço de aproximação entre ambos baseado na hipótese segundo a qual suas narrativas compartilham visões nostálgicas do passado - feudal e colonial, respectivamente - sustentadas pelo papel de destaque atribuído à linhagem.

Pretendo mostrar a seguir que, nas reflexões de Gobineau e Freyre, a centralidade conferida à família corresponde à face mais visível do elogio às estruturas intermediárias identificadas com as sociedades tradicionais e, por derivação, à crítica aos ideais abstratos embutidos na perspectiva generalista característica dos Estados modernos. Se o poder central legisla universalmente, a expansão de seus direitos, em detrimento das antigas instituições, leva de roldão os preconceitos consagrados pelos hábitos e costumes, constitutivos da esfera de exercício da liberdade. Em outros termos, ambos esposam certa concepção de liberdade que, oposta à universalidade, confunde-se com

3 Doravante denominado apenas Ottar Jarl. 
o pluralismo: ela não existe em abstrato, apenas referida aos mœurs de cada grupamento humano específico. Por isso, eles interpretam o processo de dilatação do poder público como um movimento por meio do qual o crescente nivelamento opõe-se ao exercício da liberdade, pois o Estado assume o papel de agente da uniformidade, ou seja, de promotor da igualdade par excellen$c e$. Trata-se, nos dois casos, de reinterpretações históricas predominantemente idílicas nas quais o passado é compreendido como locus privilegiado da liberdade, da heterogeneidade e da descentralização, progressivamente submetidas à potência real, que as substitui pela igualdade, pela homogeneidade e pela centralização (Gahyva, 2012b, p. 169-171).

\section{Gobineav: a derrota da família}

A construção de visões nostálgicas do passado constitui traço marcante das elaborações teóricas dos dois autores. No caso de Gobineau, o esforço remonta aos anos 1840, quando ele culpava a centralização administrativa pela falência da honra aristocrática e do espírito público, próprios à ordem medieval (Gahyva, 2012a, p. 66-69). Nessa chave, suas nostalgias feudais correspondem ao elogio à vitalidade de uma sociedade outrora heterogênea lamentavelmente entregue à letargia de um presente homogêneo.

Desde seus primeiros escritos, ele associa o processo de centralização, característico da formação do Estado nacional francês, ao ideal igualitário subjacente ao veloz movimento de aburguesamento da sociedade. Essa denúncia atravessa sua obra, constituindo principal e permanente preocupação. Em outras palavras, recusando certa vulgata gobiniana, aliás bastante difundida, lida-se, aqui, com leitura alternativa que, ao extrapolar os limites do Essai, relega a temática racial a segundo plano, pois a condiciona à defesa contundente de visão particular dos predicados da ordem feudal. Se "sua hipótese [...] é mais social e política que propriamente biológica” (Banton, 1979, p. 57-58), torna-se possível interpretar a obra de Gobineau como uma recusa radical à nova configuração política e ideológica da Europa moderna. Assim, sua teoria da miscigenação traduzia resposta particular às crescentes reivindicações democráticas próprias ao século XIX. O recurso ao argumento biológico tinha como objetivo fornecer sólidos motivos para a ruína da antiga ordem. Ao atribuir base ontológica à centralização monárquica, ele inocentava seus agentes, pois inscrevia o processo de abastardamento das localidades em um 
viés supostamente atávico que lhe possibilitava afirmar que o movimento que levou a termo a autonomia da vida provincial era o mesmo que conduziria a civilização à bancarrota.

Gobineau reconhecia na preponderância crescente que a capital francesa adquiria sobre o resto da nação contundente sintoma desse processo de amesquinhamento das raízes regionais por meio do qual a robustez e a pluralidade singulares à organização hierárquica foram irreversivelmente submetidas à ordem igualitária. Segundo ele, a concentração da vida nacional em Paris fora, em grande parte, facilitada por setores da nobreza que, ao desprezar seus direitos provinciais em troca de favores reais, desconsideraram sua função histórica. Seduzidos pelas benesses da sociedade de corte, concordaram em fazer tábula rasa do passado, abrindo mão daqueles direitos que a história - a tradição - lhes conferia. Como resultado desse processo, a França era governada por uma cidade que "não tem tradições [...]; é que Paris, a cidade de todos, não é a cidade de ninguém” (Revue Provinciale apud Boissel, 1993, p. 311, tradução minha ${ }^{4}$ ).

Quando se retira a centralidade do argumento racialista da narrativa de Gobineau, tornam-se mais evidentes suas afinidades com as perspectivas de Tocqueville. Já explorei alhures paralelos possíveis entre eles (Gahyva, 2006) - que foram, aliás, efetivamente próximos; importa, neste momento, perceber que ambos atribuíam a origem da trajetória revolucionária francesa, de um lado, à desvalorização da pluralidade regional; de outro, aos homens de letras que, sob os auspícios da razão incentivavam o desprezo às tradições. $\mathrm{O}$ argumento toma corpo em artigo escrito por Gobineau em fins dos anos 1840:

É então bastante óbvio que os homens do século XVIII que estavam à frente do movimento intelectual, gente que tinha, em grau mais ou menos parecido, rompido com os interesses e as ideias das províncias de onde vinham originalmente, tenham apaixonado-se muito mais por abstrações e teorias que lhes apresentava a ebulição dos cérebros trabalhando em seu entorno do que por estas ideias, estas noções, estas tradições múltiplas que as cidades, os burgos e os sulcos da vasta França recebiam misteriosamente no silêncio provincial. (Revue Provinciale apud Boissel, 1993, p. 311, tradução minha).

4 A Revue Provinciale foi editada por Gobineau e Louis de Kergolay entre setembro de 1848 e agosto do ano seguinte.

Horizontes Antropológicos, Porto Alegre, ano 21, n. 44, p. 371-390, jul./dez. 2015 
Situação diversa ele reconhecia na Suécia, país no qual exerceu funções diplomáticas durante os primeiros anos da década de 1870. Lá, Gobineau identificava um saudável "gosto dos proprietários por seus domínios e seus camponeses e creio ser esta uma das razões que mantém a união das classes e impede que se propague o sentimento revolucionário" (cf. Raeders, 1938, p. 126). Enquanto na França a sociedade mercantil parisiense reinava absoluta sobre o conjunto da nação, na Suécia "é a classe agrícola que fornece quase todos os membros da Dieta, donde a grande felicidade deste país; as cidades dão pouco; os deputados são, em geral, proprietários rurais ou camponeses” (cf. Raeders, 1938, p. 90-91).

Por trás da crítica de Gobineau ao processo de formação do Estado nacional francês, identifica-se seu repúdio a perspectivas generalistas que atropelam as circunstâncias em nome de abstrações supostamente universais. A simpatia pela realidade sueca, por outro lado, revela sua predileção por uma ordem social ancorada naqueles preconceitos chancelados pela tradição. No primeiro caso, identificação entre centralização e igualdade que, em sua interpretação, equivaliam à homogeneidade; no outro, elogio à liberdade, valor por princípio heterogêneo, garantido pela pluralidade própria à descentralização.

Não à toa, ele escolhe o principado de Burbach para servir de principal cenário a Les Pléiades (Gobineau, 1983b), romance no qual os superiores arianos descritos no Essai (Gobineau, 1983a) cedem lugar aos fils de roi - ou, em outros termos, narrativa que propõe uma hierarquia individual em substituição à racial. Se o inexorável movimento centralizador conduzia as sociedades a uma necessária democratização, principal sintoma de sua própria decadência, uma organização política nos moldes de um principado parecia-lhe mais propícia ao desenvolvimento das qualidades daqueles seres excepcionais que, resguardando uma heterogeneidade irreversivelmente perdida na era da unidade (Gobineau, 1983a, p. 1164), ${ }^{5}$ se mostravam capazes de transcender o vulgo.

\footnotetext{
A era da unidade representa a versão gobiniana para o fim da história. Corresponde “[...] [a]o último termo da mediocridade em todos os gêneros: mediocridade de força física, mediocridade de beleza; mediocridade de aptidões intelectuais, podendo-se quase dizer 'vazio'. Esta triste herança, cada um possuirá uma porção igual; motivo algum existe para que um tal homem tenha um lote mais rico que um tal outro; [...] todos os homens se parecem. [...] Eles terão a mesma dose de forças físicas, direções idênticas em seus instintos, medidas análogas em suas faculdades, e este nível geral, mais uma vez, será a mais revoltante humildade.” (Gobineau, 1983a, p. 1164, tradução minha).
}

Horizontes Antropológicos, Porto Alegre, ano 21, n. 44, p. 371-390, jul./dez. 2015 
O pessimismo fatalista de Gobineau fazia provisória concessão (Gahyva, 2008, p. 296-297) a certos lugares protegidos ainda aptos a reunir aqueles elementos que naufragavam no turbilhão igualitário: hierarquia, descentralização e heterogeneidade. Considerando que "a democracia é sem dúvida a forma de governo mais inconcebível para um pensador que vê na semelhança e na uniformidade categorias inimigas do Ser” (André, 1990, p. 14, tradução minha), Burbach corresponde, para ele, a uma ilha preservada no vasto e expansivo oceano democrático.

Outra ilha merece a atenção de Gobineau: é na Inglaterra que ele localiza os remanescentes de sua raça de heróis. O elogio vem em oposição à França: enquanto os insulares primavam por fusões étnicas lentas e pouco variáveis, em sua pátria natal "as raças estão mais misturadas do que qualquer outro lugar” (Gobineau, 1983a, p. 179, tradução minha). Revela-se na sua admiração pelos ingleses a crítica política e social subjacente ao léxico racial: porque menos miscigenados, eles preservariam mais do que qualquer outro povo suas antigas instituições, enquanto os franceses, ao contrário, viveram sob intensas convulsões.

O vocabulário racial constitui igualmente recurso por meio do qual Gobineau revela os constrangimentos holísticos que inviabilizam a noção de indivíduo universal. Na qualidade de produto de condicionamentos étnicos, os seres humanos jamais podem ser considerados abstratamente, apenas como resultado de cruzamentos específicos e, portanto, necessariamente circunstanciais. Reencontra-se, em sua perspectiva, condenação similar àquela que Joseph Maistre, em 1797 (Maistre, 2010, p. 180), dirigira à noção de indivíduo elaborada pelos philosophes: "Não existe o homem ideal, o homem não existe.” (Gobineau, 1983a, p. 316, tradução minha).

Nos anos 1850, Gobineau rechaçava a autonomia individual porque submetida a uma coletividade que a transcendia, o pertencimento étnico. Mas, conforme afirmado no início deste artigo, sua reflexão caminha rumo ao estabelecimento de uma hierarquia familiar, elaborada em sua citada última obra. Tanto no Essai, quanto em Ottar Jarl - respectivamente de modo indireto ${ }^{6}$ e direto - o indivíduo sucumbe à linhagem. Dentre as estruturas intermediárias identificadas com a sociedade feudal, é a família aquela que povoa com mais

6 Para as conexões entre raça e linhagem, ver Rémi-Giraud (2003) e Gahyva (2012a, p. 17-55).

Horizontes Antropológicos, Porto Alegre, ano 21, n. 44, p. 371-390, jul./dez. 2015 
intensidade as nostalgias aristocráticas do conde Arthur. Sua verve antinacional, expressa na crítica obsessiva à centralização, nutre-se da oposição que ele identifica entre o Estado e a célula familiar. A certeza desagradável, porém resignada, quanto à vitória do primeiro, encerra uma filosofia da história irreversivelmente pessimista: o movimento que rompeu o elo entre o indivíduo e a linhagem é o mesmo que conduz a civilização ocidental à ruína.

\section{Freyre: a permanência da família}

As nostalgias de Freyre driblam dificuldade constitutiva de parte significativa das narrativas voltadas ao tema da formação nacional brasileira: o tratamento ambíguo destinado ao passado colonial (Ricúpero, 2010, p. 76). Para o pernambucano, esse largo período histórico não se constitui como obstáculo à nação independente. Ao contrário, nele foi gestada a identidade nacional e, por isso, essa época sociologicamente feudal (Freyre, 1950, p. 178; Freyre, 2006, p. 64-65, 141, 170) encerra, em sua obra, imagem positiva.

Por outro lado, sua compreensão da identidade brasileira a partir da chave dos antagonismos em equilíbrio - dos quais é a miscigenação principal exemplo (Freyre, 2006, p. 116) -, possibilita-lhe driblar o pessimismo constitutivo da filosofia gobiniana da história. Enquanto o diplomata francês tende a interpretar a modernidade na chave da decadência, destacando seu furor homogeneizante, Freyre, apesar de permanentemente atento ao risco (Freyre, 1943, p. 18-19), consegue vislumbrar um Brasil moderno prenhe de seu passado.

Entretanto, como nota Bastos, a obra do pernambucano não é imune ao tema da decadência. De modo mais geral, pela própria recorrência da questão no debate característico das décadas de 1920 e 1930 (Herman, 1999, p. 235268); mais especificamente, por sua constante preocupação com a questão do abandono das tradições, principal ameaça ao equilíbrio social (Bastos, 2003, p. 44, 70). Nessa chave, se é correto afirmar que Casa-grande \& senzala, Sobrados e mocambos e Ordem e progresso podem ser interpretados sob a ótica da decadência (Araújo, 1994, p. 105; Bastos, 2003, p. 80, 2006, p. 39), "pouco a pouco, ao longo da sua argumentação, nosso autor vai chamando a atenção para a persistência de determinados componentes da tradição colonial...” (Araújo, 1994, p. 111, grifo do autor; ver também Bastos, 2003, p. 78). Trata-se da ação daquela lógica acomodatícia, capaz de aliar a agenda modernizadora ao legado civilizacional brasileiro (Carvalho, 2002, p. 894). 
Essa possibilidade de inscrição da mudança na continuidade e da continuidade na mudança (Barbu, 1981, p. 60) permite a Freyre construir, na sua trilogia sobre a constituição e o desenvolvimento da nação brasileira, uma interpretação relativamente otimista do porvir.

Casa-grande \& senzala retrocede ao período colonial para discutir os condicionantes históricos e sociais que, sob os auspícios do patriarcalismo, formaram uma identidade nacional caracterizada por tal equilíbrio de contrários. É já bastante conhecido o argumento de Freyre sobre o caráter híbrido dos colonizadores lusitanos: excepcionalidades políticas e geográficas uniram-se para formar um povo culturalmente plástico, capaz de assimilar harmonicamente elementos estranhos (Freyre, 1940, p. 39).

Os contatos com povos não europeus moldaram-lhe fisionomia singular, conferindo aos ibéricos certa rusticidade que os tornam relativamente refratários à racionalidade burguesa (Bastos, 2003, p. 100). Relativamente porque nossos colonizadores desprezam recusas ou adesões integrais - por caráter, dobram-se às circunstâncias, ignorando soluções abstratas. Se é verdade que "Gilberto Freyre contrapunha a tradição patriarcal a todos os elementos que pudessem ser constitutivos do capitalismo e da democracia” (Cardoso, 2006, p. 27), sua meta era a acomodação entre as duas tendências, pois o temperamento contemporizador não permite aos portugueses virar as costas nem para suas raízes orientais, nem para a Europa burguesa. Sendo, entretanto, produto do equilíbrio entre essas tradições, o caso ibérico problematiza a universalidade das demandas liberais, possibilitando a Freyre refutar sua plena viabilidade em sociedades híbridas - e na brasileira, em particular (Freyre, 1940, p. 42-68).

O talento flexível explica a conversão, no Brasil, dos lusitanos ao ruralismo (Freyre, 2006, p. 86). A capacidade do colonizador de curvar-se às circunstâncias possibilitou à família patriarcal cumprir a função de unidade colonizadora (Freyre, 2003, p. 63, 78; Freyre, 2006, p. 81). À sombra da casa-grande, a soma de tendências formadoras do ibérico aliou-se a influências indígenas e africanas. Por meio de peculiar relação de mão dupla entre dominados e dominantes, as orientações hierarquizantes derivadas da monocultura canavieira escravocrata foram equilibradas pela dinâmica democratizante do processo de miscigenação gestado sob a égide do patriarcalismo (Freyre, 2006, p. 435). Na plasticidade desse sistema manifesta-se "a potencialidade da cultura brasileira" (Freyre, 2006, p. 418): harmonizando os antagonismos, 
ele contornou as ameaças de ruptura subjacentes às relações verticalizadas, garantindo a preservação de aspectos centrais da ordem social.

A partir dessa forma de superação da oposição original entre senhores e escravos, a família patriarcal reeditou a flexibilidade ibérica, estabelecendo, em terras tropicais, um padrão gradual de mudança social que, extrapolando os tempos coloniais, torna-se uma constante na história nacional. Eis como, alguns anos após a publicação de sua obra inaugural, Freyre acentua a importância da preservação do nosso ímpeto conciliador:

[...] na conservação [...] de elementos da cultura tradicional está uma garantia contra a desintegração a que elas tendem, quando forçadas a abandonar rapidamente estilos tradicionais de cultura. Esse abandono, para ser social e psicologicamente saudável, tem de ser lento. (Freyre, 1940, p. 40).

Esse modo negociado de produção de consenso, elemento central da identidade brasileira, adaptou-se a substâncias variadas, permitindo que a unidade nacional abrigasse rica diversidade interna. O patriarcalismo representa um critério geral que, constrangido pelas circunstâncias, possibilita a permanência das particularidades regionais brasileiras. Ele garante, em síntese, aquela conexão entre ordem e liberdade que na Europa feudal ou no Brasil colonial via-se ameaçada pela agenda universalista e impessoal própria ao ideário moderno.

Em Sobrados e mocambos, de 1936, Freyre (2003) narra o enfraquecimento progressivo da família patriarcal, diretamente proporcional à dilatação da esfera de abrangência da burocracia estatal. O processo implicou simultaneamente o desgaste de certos freios tradicionais e a desvalorização de vários elementos culturais associados à herança “oriental”, cuja obsolescência fora decretada pela voga reeuropeizante que banha o século XIX brasileiro. No primeiro caso, o risco seria a plena substituição das tendências conciliatórias pelas dinâmicas da competição e do conflito; no segundo, a heterogeneidade regional sucumbiria à igualdade - a derrota da ordem e da liberdade, respectivamente.

Para Freyre, contudo, o processo de decadência da família patriarcal conseguiu adaptar-se à lógica da acomodação: apesar de sua retração, "tudo indica que a família entre nós não deixará completamente de ser a influência se não criadora, conservadora e disseminadora de valores, que foi na sua 
fase patriarcal” (Freyre, 2003, p. 78). Essa dinâmica é reiterada no terceiro e derradeiro volume da trilogia freyriana sobre a formação brasileira, Ordem e progresso, de 1958, obra na qual ele revela como, na passagem do Império à República, nossas virtudes apaziguadoras impuseram-se sobre possíveis soluções de ruptura:

Oficialmente este [patriarcado agrário e escravocrático] teria morrido de vez no Brasil um ano antes de iniciar-se o período republicano. Sociologicamente, não morreu: já ferido de morte pela Abolição acomodou-se à República federativa quase tão simbioticamente como outrora o patriarcado escravocrático se acomodara ao Império unitário. (Freyre, 1990, p. XLVIII).

Ou seja, Freyre narra, nesses três livros, o processo singular por meio do qual o poder privado - a família - vai cedendo, no Brasil, espaço para o poder público - o Estado: sua marca é a conciliação (Bastos, 2006, p. 14).

\section{Considerações finais}

A visão positiva do pernambucano quanto às possibilidades futuras da nação brasileira funda-se no mesmo pressuposto do pessimismo de Gobineau. Na concepção de ambos, apenas a linhagem, célula básica da vida social, seria capaz de zelar pela tradição e pela pluralidade ameaçadas pela sanha homogeneizadora própria à modernidade ocidental. Para o francês, entretanto, a ameaça já se concretizara: sua hierarquia familiar nascia sob o signo da provisoriedade, pois a alteração do princípio distintivo - da raça à família - não impedia que Ottar Jarl reeditasse a resignação fatalista do Essai, de modo que, nos dois casos, a tentativa de regeneração sucumbia à era da unidade (Gahyva, 2013, p. 253).

Freyre às vezes parecia não vislumbrar futuro diferente à Europa carbonífera e burguesa (Freyre, 1943, p. 192; Freyre, 2003, p. 517), mergulhada num cosmopolitismo urbano que cada vez mais atribuía às particularidades regionais sentido único (Freyre, 1943, p. 120-21). Ao mundo lusotropical e brasileiro, em especial -, todavia, parecia-lhe reservado destino diverso. Nossa matriz conciliatória teria engendrado a excepcionalidade histórica que nutria suas esperanças: no Brasil, não teria havido oposição histórica radical entre família e Estado. 
Na relação de complementariedade entre ordem pública e privada reside a chave para a superação do antagonismo histórico entre igualdade e liberdade. No caso brasileiro, a plasticidade do patriarcalismo teria garantido a conciliação entre as tendências unificadoras do binômio urbanização-industrialização e a pluralidade regional. Trata-se da elaboração de formas alternativas de modernidade que, sob a égide nacional, baseiam-se na interação entre orientações universalistas e costumes locais - o que implica, necessariamente, a relativização das premissas igualitárias, ou, no limite, sua submissão aos princípios da liberdade.

Em Casa-grande \& senzala, a procedência do talento para harmonizar opostos é, como se viu, atribuída à herança portuguesa; em Ordem e progresso, a qualidade outrora identificada aos nossos colonizadores torna-se "virtude britânica” (Freyre, 1990, p. 8). Tanto num caso quanto no outro, trata-se de apologia à contemporização. Nesse sentido, pode-se sugerir que a lusofilia de Freyre justificava sua adesão ao reformismo à inglesa (Carvalho, 2002, p. 894), como revela seu elogio aos artífices da república brasileira:

Progressistas eram eles decerto [...] mas não ao ponto de se esquecerem da tradição de ordem, que vinha concorrendo para dar ao Brasil um dos seus característicos nacionais mais fortes; e destacando-o dos povos americanos de língua espanhola e de tendências bolivarianas, para aproximá-lo, nesse particular, dos próprios anglo-saxões do continente, progressistas, é certo, mas, como os anglo-saxões da Europa, inclinados, há mais de dois séculos, a realizar seus progressos técnicos e suas transformações sociais dentro do máximo de ordem política. (Freyre, 1990, p. 15-16).

Discutiu-se mais acima o estatuto da experiência inglesa na narrativa de Gobineau: sua potencialidade não ultrapassa a dimensão nostálgica. Vencida pela universalidade moderna, a sabedoria conciliatória tornou-se irreversivelmente residual. Em Freyre, a solução é menos clara: em contraste com a citação anterior, há outros momentos nos quais os anglo-saxões, historicamente conciliadores, são também os atuais portadores privilegiados de uma civilização escrava do tempo cronométrico (Freyre, 1973, p. 25).

Nesse caso, pouco importa o viés privilegiado. Para ele, as habilidades acomodatícias tornaram-se patrimônio do mundo lusotropical (Freyre, 1940, p. 68). Se a Ibéria cultiva certa concepção de tempo tornada anacrônica na era da modernização capitalista, Freyre (1973, p. 11) reconhece nesses “aparentes 
arcaísmos repelidos por intolerâncias modernistas” as condições de possibilidade do exercício da liberdade. Trata-se da identificação de um tempo hispânico, avesso ao planejamento, o tempo tríbio (Freyre, 1990, p. XXI-XXVII).

Na obra do pernambucano, a crítica ao tempo linear, universal, não se traveste de extemporânea visão cíclica (Koselleck, 2006, p. 43), mas de concepção espiralada na qual o ritmo da mudança é ditado pela articulação sociológica entre passado e presente (Freyre, 1990, p. XXXIX). ${ }^{7}$ Nesse processo "a tradição, incorporada a uma civilização, passava a ser considerada condição contemporânea da existência viva dessa civilização: parte inevitável da sua atualidade” (Freyre, 1990, p. CLXVIII).

Mas se a origem dessa forma de experimentar o tempo é hispânica, o Brasil deve cumprir papel de protagonista da civilização lusotropical (Meucci, 2010, p. 329). "Somos um povo, mais que o anglo-americano, ligado, em nossa existência, ao passado, embora também americanamente sensível ao presente e ao futuro.” (Freyre, 1990, p. XL). Ao Novo Mundo tropical, locus privilegiado do cruzamento entre tradição e modernidade, cabe a missão de equilibrar harmonicamente aquelas duas temporalidades, ditando o compasso e a feição do futuro. Fiel, porém, à associação entre ordem, liberdade e manutenção dos costumes, Freyre reitera um pluralismo preferencialmente circunscrito ao espaço de experiência (Koselleck, 2006, p. 43), pois a interdependência entre os três tempos tende a obedecer os comandos do passado (Freyre, 1990, p. CLXIX).

Sua recomendação é clara: se o futuro próximo aponta para o esgotamento de um padrão civilizacional ancorado no culto ao "homem econômico" (Freyre, 1943, p. 174), permanentemente submetido ao tempo cronométrico, a alternativa não se encontra nas tentativas de planificação da vida, ou seja, no reforço do élan homogeneizador que, segundo ele, apenas recrudesceria

\footnotetext{
Se, por um lado, Freyre identifica no passado uma unidade harmônica abalada pelo processo de modernização (Bastos, 2003, p. 63), seu lamento não ignora a necessidade de mudanças, tal como revela seu elogio aos bandeirantes: "Sem desprezo pelas tendências à conservação, à estabilidade e até à rotina ou mesmo à inércia - tendências talvez indispensáveis à aristocratização de um grupo humano ou de uma época - temos que reconhecer, nos indivíduos e subgrupos mais ansiosos de inovar, aquela outra aristocracia não direi biológica, como expressão de raça superior [...], mas talvez psicológica, neste sentido: em considerar-se o indivíduo ou o subgrupo inovador, superior ao conjunto de normas sociais e de cultura estabelecido e aceito pela maioria inerte, cujos valores e estilos de vida se julga no dever - noblesse oblige - de retificar ou renovar, de ampliar ou expandir. Nessa expansão de valores de cultura e de vida é que principalmente se afirmam as minorias ativas e inovadoras.” (Freyre, 1943, p. 83).
}

Horizontes Antropológicos, Porto Alegre, ano 21, n. 44, p. 371-390, jul./dez. 2015 
a submissão individual ao Estado (Freyre, 1943, p. 174-175). As expectativas de Freyre voltam-se ao mundo que o português criou nos trópicos, cuja originalidade reside na forma como a lógica acomodatícia plasmada sob o patriarcalismo, ao penetrar na esfera pública, permitiu a adaptação dos valores modernos à organização pluralista.

Se a importância atribuída à célula familiar é chave possível para o estabelecimento de afinidades entre sua narrativa e a de Gobineau, Freyre reconhece, no Brasil, certa continuidade histórica entre linhagem e Estado capaz de contrabalançar as ameaças provenientes da igualdade moderna. Para o conde Arthur, em oposição, o Estado nacional francês, formado às expensas das linhagens, somado à sua consequência lógica, a Revolução, neutralizaram as potencialidades inscritas na lógica familiar. Nesse movimento, ela perdeu seu papel histórico de guardiã das tradições e fomentadora da diversidade.

O pessimismo gobiniano, viu-se mais acima, deriva da certeza quanto ao irreversível divórcio entre família e Estado - ou, em outros termos, entre liberdade e igualdade. Freyre não se enclausura na era da unidade: ainda que sua obra aponte permanentemente para as ameaças de desequilíbrio que pontuam a história brasileira, a "primeira sociedade moderna constituída nos trópicos com características nacionais e qualidades de permanência” (Freyre, 2006, p. 73) revela-se espécie de nova Inglaterra, reatualizando suas expectativas quanto a uma visão otimista do futuro. Assim, se a persistência da linhagem representa o solo comum a partir do qual ambos avaliam a modernidade, Gobineau e Freyre extraem dessa premissa consequências diversas: enquanto o primeiro recusa-se a dialogar com os tempos modernos, decretando sua ruína, o pernambucano dribla a decadência ao vislumbrar para o Brasil um protagonismo civilizatório capaz de manter e generalizar sua excepcionalidade histórica.

\section{Referências}

ANDRÉ, S. Gobineau: parcours mythiques d'une œuvre. Paris: Lettres Modernes, 1990.

ARAÚJO, R. B. Guerra e paz: “Casa-grande \& senzala” e a obra de Gilberto Freyre nos anos 30. Rio de Janeiro: Ed. 34, 1994. 
BANTON, M. A ideia de raça. Lisboa: Edições 70, 1979.

BARBU, Z. A contribuição de Gilberto Freyre à sociologia histórica. In: GILBERTO FREYRE na UnB: conferências e comentários de um simpósio internacional realizado de 13 a 17 de outubro de 1980. Brasília: Editora Universidade de Brasília, 1981. p. 49-65.

BASTOS, E. R. Gilberto Freyre e o pensamento hispânico: entre Dom Quixote e Alonso El Bueno. Bauru: EDUSC, 2003.

BASTOS, E. R. As criaturas de prometeu: Gilberto Freyre e a formação da sociedade brasileira. São Paulo: Global, 2006.

BOISSEL, J. Gobineau: biographie (mythes et réalité). Paris: Berg International, 1993.

CARDOSO, F. H. Um livro perene. In: FREYRE, G. Casa-grande \& senzala: formação da família brasileira sob o regime da economia patriarcal. São Paulo: Global, 2006. p. 19-28.

CARVALHO, M. A. R. Casa-grande \& senzala e o pensamento social brasileiro. In: FREYRE, G. Casa-grande \& senzala: edição crítica. Madrid: ALLCA XX, 2002. p. 877-908.

CASSIRER, E. El mito del Estado. México: Fondo de Cultura Económica, 1997.

DREYFUS, R. Le cas Gobineau: Gobineau est-il responsable de Hitler?. Revue de Paris, Paris, v. 5, p. 588-610, sept. 1933.

FREYRE, G. O mundo que o português criou. Rio de Janeiro: José Olympio, 1940.

FREYRE, G. Problemas brasileiros de antropologia. Rio de Janeiro: Casa do Estudante, 1943.

FREYRE, G. Quase política. Rio de Janeiro: José Olympio, 1950. 
FREYRE, G. Além do apenas moderno: sugestões em torno de possíveis futuros do homem, em geral, e do homem brasileiro, em particular. Rio de Janeiro: José Olympio, 1973.

FREYRE, G. Ordem e progresso. Rio de Janeiro: Record, 1990.

FREYRE, G. Sobrados e mocambos: decadência do patriarcado rural e desenvolvimento do urbano. São Paulo: Global, 2003.

FREYRE, G. Casa-grande \& senzala: formação da família brasileira sob o regime da economia patriarcal. São Paulo: Global, 2006.

GAHYVA, H. Tocqueville e Gobineau no mundo dos iguais. Dados, Rio de Janeiro, v. 49, n. 3, p. 553-582, 2006.

GAHYVA, H. Em Burbach sou amigo do rei: um estudo sobre Les Pléiades, de Arthur de Gobineau. Escritos: Revista da Fundação Casa de Rui Barbosa, Rio de Janeiro, ano 2, n. 2, p. 283-300, 2008.

GAHYVA, H. Tempos da casa-grande: as primeiras críticas à obra inaugural de Gilberto Freyre. Revista de Ciências Humanas, Viçosa, v. 10, n. 2, p. 245255, 2011a.

GAHYVA, H. A epopeia da decadência: um estudo sobre o Essai sur l'inégalité des races humaines (1853-1855), de Arthur de Gobineau. Mana: Estudos de Antropologia Social, Rio de Janeiro, v. 17, n. 3, p. 501-518, 2011 b.

GAHYVA, H. O inimigo do século: um estudo sobre Arthur de Gobineau (1816-1882). Rio de Janeiro: Mauad X, 2012a.

GAHYVA, H. De Boulainvilliers a Tocqueville: da liberdade como defesa de privilégios à liberdade como defesa de diferenças. Sociologias, Porto Alegre, ano 14, n. 31, p. 168-190, set./dez. 2012b.

GAHYVA, H. O bom filho a casa torna: Gobineau refugiado na hierarquia familiar. Tempo Social, São Paulo, v. 25, n. 1, p. 235-256, 2013.

GOBINEAU, A. de. Histoire d'Ottar Jarl: pirate norvégien, conquérant du pays de Bray en Normandie et de sa descendance. Paris: Didier et Cie., 1879. 
GOBINEAU, A. de. Essai sur l'inégalité des races humaines. In: GOBINEAU, A. de. Euvres: tome I. Paris: Gallimard, 1983a. p. 133-1174.

GOBINEAU, A. de. Les Pléiades. In: GOBINEAU, A. de. CEuvres: tome III. Paris: Gallimard, 1983b. p. 3-302.

HERMAN, A. A ideia de decadência na história ocidental. Rio de Janeiro: Record, 1999.

KOSELLECK, R. Futuro passado: contribuição à semântica dos tempos históricos. Rio de Janeiro: Contraponto, 2006.

KUJAWSKI, G. Gilberto Freyre, escritor ibérico. In: GILBERTO FREYRE na UnB: conferências e comentários de um simpósio internacional realizado de 13 a 17 de outubro de 1980. Brasília: Editora Universidade de Brasília, 1981. p. 15-19.

LEITE, D. M. O caráter nacional brasileiro: história de uma ideologia. São Paulo: Editora Unesp, 2002.

LIMA, L. C. A versão solar do patriarcalismo: Casa-grande \& senzala. In: LIMA, L. C. A aguarrás do tempo: estudos sobre a narrativa. Rio de Janeiro: Rocco, 1989. p. 187-238.

MAISTRE, J. Considerações sobre França. Coimbra: Almedina, 2010.

MEUCCI, S. O mundo português criado por Gilberto Freyre: fundamentos, efeitos e possibilidades do luso tropicalismo nos anos 1950. In: BOTELHO, A.; FERREIRA, G. N. Revisão do pensamento conservador: ideias e política no Brasil. São Paulo: Hucitec: Fapesp, 2010. p. 311-343.

MOTA, C. G. Ideologia da cultura brasileira (1933-1974). São Paulo: Ática, 1977.

PESAVENTO, S. J. De Recife para o mundo. In: DIMAS, A.; LEENHARDT, J.; PESAVENTO, S. J. (Org.). Reinventar o Brasil: Gilberto Freyre entre história e ficção. Porto Alegre: Editora da UFRGS: Editora da USP, 2006. p. 41-65. 
RAEDERS, G. (Org.). D. Pedro II e o Conde de Gobineau: correspondências inéditas. São Paulo: Companhia Editora Nacional, 1938.

RÉMI-GIRAUD, S. Le mot race dans les dictionnaires français du XIXe siècle. In: MOUSSA, S. (Dir.). L'idée de race dans les sciences humaines et la littérature (XVIIe et XIX siècles): actes du colloque international de Lyon (16-18 novembre 2000). Paris: L’Harmattan, 2003. p. 203-221.

RICÚPERO, B. O conservadorismo difícil. In: BOTELHO, A.; FERREIRA, G. N. Revisão do pensamento conservador: ideias e política no Brasil. São Paulo: Hucitec: Fapesp, 2010. p. 76-94.

SEVCENKO, N. Gilberto Freyre e a mídia: pioneirismo, sensibilidade e inovação. In: ARAÚJO, R. M. B.; FALCÃO, J. (Org.). O imperador das idéias: Gilberto Freyre em questão. Rio de Janeiro: Topbooks, 2001. p. 46-54. 